\title{
CORRIGENDUM
}

\section{Single-taxon field measurements of bacterial gene regulation controlling DMSP fate}

\author{
Vanessa A Varaljay, Julie Robidart, Christina M Preston, Scott M Gifford, \\ Bryndan P Durham, Andrew S Burns, John P Ryan, Roman Marin III, Ronald P Kiene, \\ Jonathan P Zehr, Christopher A Scholin and Mary Ann Moran
}

The ISME Journal (2015) 9, 1692; doi:10.1038/ismej.2015.94

Correction to: The ISME Journal (2015) 1677-1686; doi: 10.1038/ismej.2015.23; published online 20 February 2015

A wording error in a sentence in the abstract misrepresented a main finding of the research. The sentence should read:

Expression of the demethylation pathway was relatively greater during a high-DMSP-producing dinoflagellate bloom, and expression of the cleavage pathway was greater in the presence of a mixed diatom and dinoflagellate community.

The sentence has now been corrected.

The supplementary file published with the paper was missing figure legends. The correct file is now provided. 